\title{
Nanotechnology Attitude Scale Development Study for Pre-Service Science Fields Teachers
}

\author{
Tuba Şenel Zor ${ }^{*}$, Adnan Kan² \\ ${ }^{1}$ Science Education Department, Gazi University, Turkey \\ ${ }^{2}$ Guidance and Psychological Counseling Department, Gazi University, Turkey \\ *Corresponding Author tubasenell@gmail.com
}

\begin{abstract}
This study aims to develop a measurement tool to measure pre-service science fields teachers' (PSSFT') attitudes towards nanotechnology. For this purpose, a five-point Likert-type scale consisting of 55 items was applied to 373 PSSFT who enrolled in science fields (Science, Chemistry, Biology, Physics) at the grades $1^{\text {st }}, 2^{\text {nd }}, 3^{\text {rd }}$, and $4^{\text {th }}$ at a public university in Turkey. The exploratory factor analysis (EFA) determined that the scale had a 3-factor structure consisting of 24 items and the factors explained $55.854 \%$ of the attitude variable's total variance. Verification of the model was tested by applying confirmatory factor analysis (CFA). The CFA data were obtained from 770 PSSFT enrolled in science fields at the grades $1^{\text {st }}, 2^{\text {nd }}, 3^{\text {rd }}$, and $4^{\text {th }}$ at two different public universities in Turkey. The results obtained from CFA were in agreement with the model obtained by EFA. Cronbach's alpha $(\mathrm{Cr}-\alpha)$ reliability of the scale was calculated to be 0.926 . Findings from the validity and reliability analyses show that the scale is a valid and reliable measurement tool that can measure PSSFT' attitudes towards nanotechnology.
\end{abstract}

Keywords Attitude, Nanotechnology, Pre-service science fields teachers, Scale development

\section{INTRODUCTION}

Attitude research has been one of the main topics of social psychology for many years (Kağıtçıbaşı \& Cemalcılar, 2014; Oppenheim, 2001). The reason for this great interest shown in the attitude studies is that the attitudes of the individuals affect both individual's social perceptions and behaviors (Kağıtçıbaşı \& Cemalcılar, 2014). The accurately measuring of a person's attitudes towards any subject or object firstly depends on correctly identifying this characteristic (Tezbaşaran, 2008). It has been described by many researchers in the literature (Allport, 1935; Droba, 1933; İnceoğlu, 2010; Tezbaşaran; 2008). According to Thurstone (1931), attitude is the degree of emotions towards an object or person. For an individual, anything such as a house, neighbor, loved or disliked people, friends, and profession can be a psychological object. Therefore, the individual may have certain attitudes towards them (Kağıtçıbaşı \& Cemalcılar, 2014).

Attitudes are composed of three components: cognitive, affective, and behavioral (İnceoğlu, 2010). Kağıtçıbaşı and Cemalcılar (2014) described the cognitive component as the knowledge and thoughts that the individual has towards the attitude object, the affective component as the emotions of the individual towards the attitude object, and the behavioral component as the behavior tendency of the individual triggered by the attitude object. Among these components constituting the attitude, it is generally assumed that an organization brings internal consistency. According to this, what the individual knows about the subject (the cognitive component) determines what kind of emotion they will approach it with (affective component) and what kind of an attitude they will put against it (the behavioral part) (İnceoğlu, 2010).

Attitudes have an essential place in many of our social life, such as education, business, politics, entertainment, fashion, marriage, and communication. That is the main reason for social psychologists' efforts to measure attitudes (Oppenheim, 2001). Because measuring the attitudes and the level of attitudes individuals have towards the object or situation is a desirable situation in many areas (Erkuş, 2003). Various methods have been developed to measure attitudes that play such an important role in social interactions (Kuppuswamy, 1965). However, they are not directly observable because most of the individual's attitudes are usually dormant and are expressed in the form

Received: 22 Maret 2020

Revised: 10 Desember 2020

Published: 27 January 2021 
of speech or behavior only when the relevant object is perceived. Attitudes can be measured indirectly by making inferences from these observable behaviors of the individual. This measurement process requires an appropriate scale (Erkuş, 2003; Kuppuswamy, 1965).

\subsection{Nanotechnology and Attitudes towards Nanotechnology}

Nanotechnology is a new, perhaps somewhat unclear, and controversial field attracting the attention of many nations and the community of scientists interested in science communication and society's perceptions of science (Stephens, 2005). It is also a rapidly developing interdisciplinary field to be a major influence on the lives of future generations (Nerlich, Clarke, \& Ulph, 2007). Researches on nanotechnology show that there can be revolutionary developments in materials and manufacturing, electronics, medicine, health services, energy, biotechnology, information technologies, and national security. For this reason, nanotechnology is widely referred to as "the industrial revolution of the future" (Bhushan, 2010; Ç1rac1, 2006). At this point, society's views will significantly impact research and development activities (Nerlich, Clarke, \& Ulph, 2007). In other words, the future position of nanotechnology may shape by society's attitude towards nanotechnology (acceptance of nanotechnology, resistance to nanotechnology, or rejection of nanotechnology) (Roco \& Bainbridge, 2001). Therefore, it is considered that the measurement of attitudes towards nanotechnology is of great importance to fully utilize the potential of nanotechnology. However, the studies on nanotechnology attitudes' determination are relatively limited numbers when considered the relevant literature (Bainbridge, 2002; Lee, Scheufele, \& Lewenstein, 2005; Nerlich, Clarke, \& Ulph, 2007).

The studies on nanotechnology attitudes were carried out with participants of different ages and education levels using various data collection tools and methods. For example, Bainbridge (2002) collected data from 3909 participants via an internet questionnaire. Another research was conducted by Lee, Scheufele, \& Lewenstein (2005) in the US, and the data collected via a telephone survey. Liang et al. (2015) compared public attitudes towards nanotechnology in the United States and Singapore. The data collected through an online survey for the US and computer-assisted telephone interviewing software for Singapore. The superior results of these studies showed that (i) the participants had high levels of enthusiasm for the potential benefits of nanotechnology and little concern about possible dangers (Bainbridge, 2002); (ii) the participants' awareness of nanotechnology generally was low, and the media was one of the strongest predictors of attitudes towards nanotechnology (Lee, Scheufele, \& Lewenstein, 2005); (iii) Singaporeans tend to be more knowledgeable about and familiar with nanotechnology than the US public, and they also have more positive attitudes towards nanotechnology (Liang et al., 2015).

\subsection{Significance}

A deeper understanding of society's attitude towards nanotechnology will undoubtedly prove beneficial in furthering nanotechnology's responsible development worldwide (Zhang, Wang, \& Lin, 2015). At this point, teachers and pre-service teachers educating the youth of society who will become the responsible decision-makers and leaders of the next generation can have a crucial role. Teachers' knowledge, opinions, and beliefs directly influence their classroom practice (Brickhouse, 1990; Pajares, 1992). When nanotechnology's interdisciplinary nature (Tessman, 2009) considers, it is concluded that determining especially science fields teachers and preservice teachers' attitudes towards nanotechnology is essential. Therefore, it is necessary to determine the attitudes towards nanotechnology by using appropriate tools and providing the support needed to develop these attitudes following the results obtained.

When the studies investigating the attitudes towards nanotechnology are examined, it is seen that the use of measurement tools that are specifically developed to measure the attitudes towards nanotechnology and which provide quantitative data are relatively limited. In line with this situation, the scarcity of the Likert-type measurement tools designed to measure nanotechnology attitudes is also noteworthy (Kurnaz \& Bayraktar, 2012; Seçken, 2009; Lan, 2012). Thus, it can be said that a variety of measurement tools are needed. By looking at this deficiency, the present study aims to develop a scale that can be used to measure the attitudes of PSSFT towards nanotechnology.

\section{METHOD}

This study consisted of two main parts. In the first part of the study, the development of the nanotechnology attitude scale was focused. In this process, validity (EFA for construct validity) and reliability analyzes explained in the following sections were carried out. In the second part, whether the scale developed in the first part gives the same structure on a different group with similar characteristics was examined (CFA for construct validity).

\subsection{Study Group}

The first part of this study was conducted with 373 PSSFT enrolled in Science ( $\mathrm{N}=274)$, Chemistry $(\mathrm{N}=46)$, Biology ( $\mathrm{N}=35)$, and Physics $(\mathrm{N}=18)$ Education Departments at the grades $1 \mathrm{st}, 2 \mathrm{nd}, 3 \mathrm{rd}$, and 4th at a public university in Turkey's Central Anatolia region.

The second part of the study was conducted with 770 PSSFT enrolled in Science ( $N=509)$, Chemistry $(N=101)$, Biology ( $\mathrm{N}=90)$, and Physics $(\mathrm{N}=70)$ Education Departments at the grades 1st, 2nd, 3rd, and 4th, at two different public universities in Turkey's Central Anatolia region. 
Table 1 Distribution of the items according to components of attitude

\begin{tabular}{lllll}
\hline \multirow{2}{*}{ Items } & \multicolumn{2}{l}{ Components } & \multirow{2}{*}{ Total } \\
\cline { 2 - 4 } & Cognitive & Affective & Behavioral & \\
\hline Positive & 13 & 12 & 17 & 42 \\
Negative & 10 & 10 & 7 & 27 \\
Total & 23 & 22 & 24 & 69 \\
\hline
\end{tabular}

The following criteria were taken into consideration in the selection of this study group:

Ensuring heterogeneity to obtain variance: These universities have student diversity from different parts of Turkey and the world.

Target group: The scale to be developed in this study is for PSSFT, and the selected universities have adequate PSSFT providing a sample size explained at the end of this section.

Nanotechnology experience: Target groups have different experiences in nanotechnology. In general, 1st and 2nd grade PSSFT did not have any nanotechnology experience, whereas 3rd and 4th grade PSSFT encountered nanotechnology in different courses' content.

In the literature about scale development, various researchers have reported different opinions about the sample size. For example, Tinsley \& Tinsley (1987) suggested sample size should be 5-10 respondents per item up to about 300 subjects. According to Comrey and Lee (1992), the sample size might be evaluated as 50-very poor; 100-poor; 200-fair; 300-good; 500-very good; and 1000 or more excellent. In light of these previous studies, it can be concluded that the present study has an adequate sample size with 373 respondents for EFA and 770 respondents for CFA.

\subsection{Development of the Scale}

In the development of the scale, the scale development phases expressed by Crocker \& Algina (2006) were taken as the basis. Firstly, the literature about the structure, indicators, measurement of the attitude, and characteristics of attitude scales was reviewed. Later, attitude scales developed by other researchers on similar and different topics were examined. Considering these scales and the structure of the attitude, 69 items were listed to measure the attitudes towards nanotechnology. Attention has been paid because these points represent the attitude's components, and the positive and negative expressions are at similar ratios (see Table 1).

After completing the item writing process, 14 items were removed from the scale and the expression of 5 items was rearranged in line with the field experts' opinions examining the items. As a result, a 55-item trial form was created. While setting the order of the items within the scale, attention has been paid to randomly distribute the items belonging to different components and reporting positive and negative attitudes. Five response categories
(Strongly Agree=5, Strongly Disagree=1) were formed to determine the agreement levels of the PSSFT on the items in the scale. By adding the instruction that includes the purpose of the scale and the application information, the trial scale form has been made ready.

\subsection{Collection of Data}

Stage first, the purpose of the study was explained to the PSSFT, and they were informed that participation in the study was based on volunteerism. The data collection process lasted for two weeks, during which the PSSFT used about 10-12 minutes to reply to the trial scale form.

\subsection{Analysis of Data}

The data obtained by applying the trial scale to the PSSFT were analyzed by Statistical Package for the Social Sciences (SPSS) version 21 and Linear Structural Relation Statistics Package Program (LISREL) version 8.71. The SPSS is a computer program that can be used to calculate many of the descriptive (e.g., standard deviations, z scores, and correlations) and inferential (e.g., independent and repeated measures, t-tests, analysis of variance) statistics (Fraenkel \& Wallen, 2009). LISREL is a computer program developed by Jöreskog and Sörbom (1978). It allows for various analyses such as path analysis, EFA and CFA, cross-lagged panel analysis, and Markov modeling (Tinsley \& Tinsley, 1987).

The values reverse items included in the scale were corrected by re-grading after the data was transferred to the software in data analysis. Various analyzes were made on the obtained data to establish reliability and validity. These analyzes can be summarized as follows.

EFA and CFA to provide evidence of the scale's validity:

The factor analysis is often used to develop and validate psychometric instruments or testing theories about tools (Tinsley \& Tinsley, 1987). To understand the factor analysis, it may help explain the concept of "factor" first. A factor is a linear combination or cluster of related observed variables representing a specific underlying dimension of a construct correlated with one another but mostly independent of other subsets of variables (Pett, Lackey, \& Sullivan, 2003; Tabachnick \& Fidell, 2013). Factor analysis attempts to achieve parsimony by explaining the maximum amount of shared variance in a correlation matrix using the smallest number of exploratory constructs known as a factor (Field, 2013).

There are two basic types of factor analysis: EFA and CFA. EFA aims to determine the factor structure or model for a set of variables (Stevens, 2009). This analysis is implemented when the researcher does not know how many factors must clarify the interrelationships among a set of characteristics, indicators, or items (Pedhazur \& Schmelkin, 1991; Pett, Lackey, \& Sullivan, 2003; Tabachnick \& Fidell, 2013). In contrast, CFA is used to confirm a particular pattern of relationships predicted based on theory or previous analytic results (DeVellis, 
2003). It is preferred when the researcher "knows" how many factors exist and whether they should be correlated. The researcher also generally forces items to load only on a specific factor and wishes to "confirm" a hypothesized factor structure with data (Stevens, 2009).

While making EFA, generally more traditional statistical computer packages programs like SPSS, Statistical Analysis Software, and Bio-Medical Data Package are usually used (Pett, Lackey, \& Sullivan., 2003). In this study, the EFA was carried out through the SPSS program to determine the scale's factor structure and provide evidence for construct validity. In this process, rotated principal component analysis (PCA) was used as an analysis method. The varimax (orthogonal) rotation was selected as the rotation method and was not limited to factor number. PCA tries to explain the maximum amount of total variance (not just common variance) in a correlation matrix by transforming the original variables into linear components (Field, 2013). Rotation is ordinarily used after extraction to maximize high correlations between factors and variables and minimize low ones. In other words, rotation aims to obtain more specific factor loads (FL). Varimax is a variancemaximizing procedure. The varimax rotation goal is to maximize factor loadings' variance by making high loadings higher and low ones lower for each factor (Tabachnick \& Fidell, 2013).

CFA can be achieved through various statistical programs that require the use of structural equation models (Pedhazur \& Schmelkin, 1991). LISREL is the most commonly used program for this purpose (Jöreskog \&
Sörbom, 1993; Tabachnick \& Fidell, 2013). In line with relevant literature, LISREL was used for CFA in this study.

The Kaiser-Meyer Olkin (KMO) coefficient and the Barlett Sphericity test to determine the suitability of the data obtained from the scale for PCA:

KMO coefficient (Kaiser, 1970) is a statistical method which is used to determine whether the data and sample size are appropriate and adequate for the selected analysis. The KMO statistic varies between 0 and 1, and as the $\mathrm{KMO}$ coefficient approaches 1 , it means that the data is suitable for the analysis, and 1 is the perfect fit (Field, 2013). The acceptable KMO coefficient is expected to be greater than .5 (Kaiser, 1974).

In the parametric method, the measured property should have a normal distribution in the universe. The Barlett Sphericity test is a statistical technique used to check whether the data comes from a multivariate normal distribution. Chi-square test statistic is obtained end of this test. If the chi-square test statistics has a significant value, it indicates that the data comes from the multivariate normal distribution (Field, 2013; Raykov \& Marcoulides, 2008).

Item-test correlations (ITCs) were examined to provide evidence of item validity. The $\mathrm{Cr}-\alpha$ coefficient was calculated to provide evidence of reliability. There are various methods used to calculate the reliability coefficient. These methods are grouped under two headings; (i) the methods based on single test administration and (ii) the methods based on two test administrations, depending on the situation where the data to be used in estimating the reliability coefficient is obtained. The $\mathrm{Cr}-\alpha$ coefficient is

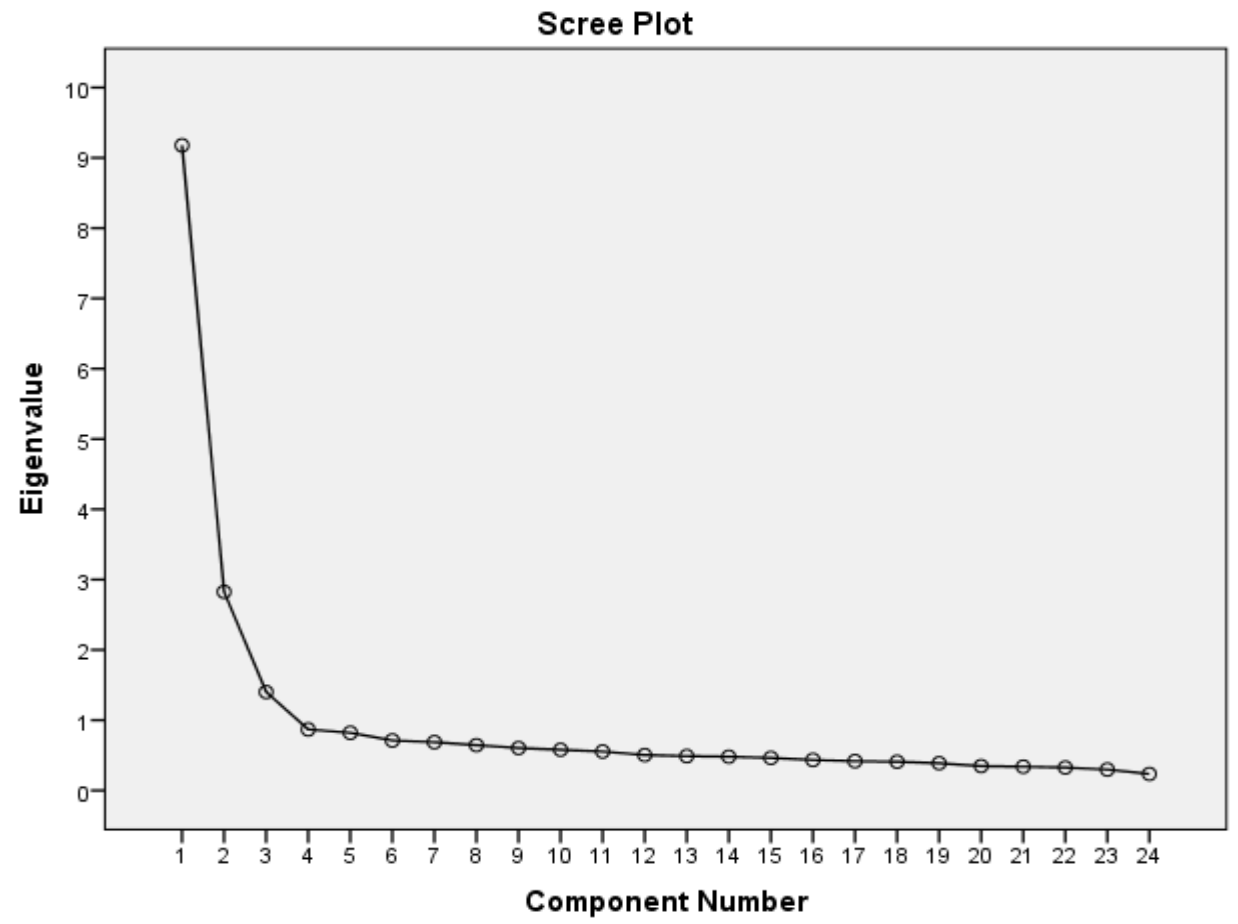

Figure 1 Scree-plot graphic of the scale 
Table 2 The results of validity and reliability analysis of attitude scale towards nanotechnology

\begin{tabular}{|c|c|c|c|c|c|}
\hline \multirow[t]{2}{*}{ 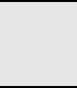 } & \multirow[t]{2}{*}{ Item } & & \multicolumn{3}{|c|}{ FL / ITC / Cr- $\alpha$ WIR* } \\
\hline & & & F1 & F2 & F3 \\
\hline \multirow{9}{*}{ 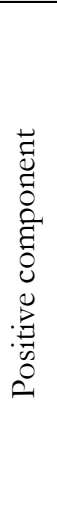 } & I54 & $\begin{array}{l}\text { If I have an opportunity, I organize nanotechnology } \\
\text { activities. }\end{array}$ & $.803 / .713 / .884$ & & \\
\hline & I53 & $\begin{array}{l}\text { I would like to create a website/blog on } \\
\text { nanotechnology. }\end{array}$ & $.799 / .745 / .882$ & & \\
\hline & $\mathrm{I} 40$ & I research about nanotechnology. & $.763 / .670 / .888$ & & \\
\hline & I55 & $\begin{array}{l}\text { If I have an opportunity, I provide that } \\
\text { nanotechnology is given as a course. }\end{array}$ & $.719 / .608 / .893$ & & \\
\hline & I49 & I follow publications related to nanotechnology. & $.689 / .606 / .893$ & & \\
\hline & $\mathrm{I} 29$ & I want to make a career in the nanotechnology field. & $.671 / .697 / .886$ & & \\
\hline & I16 & I want to prepare a nanotechnology curriculum. & $.655 / .662 / .888$ & & \\
\hline & $\mathrm{I} 34$ & I like talking about nanotechnology. & $.624 / .657 / .889$ & & \\
\hline & I48 & $\begin{array}{l}\text { I feel comfortable in nanotechnology themed } \\
\text { training or activities. }\end{array}$ & $.600 / .637 / .890$ & & \\
\hline \multirow{9}{*}{ 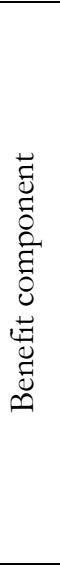 } & I19 & $\begin{array}{l}\text { Nanotechnology affects economic activities } \\
\text { positively. }\end{array}$ & & $.752 / .647 / .880$ & \\
\hline & $\mathrm{I} 13$ & $\begin{array}{l}\text { Nanotechnology provides to obtain more efficient } \\
\text { products. }\end{array}$ & & $.707 / .625 / .882$ & \\
\hline & $\mathrm{I} 30$ & $\begin{array}{l}\text { I believe that nanotechnology will make our life } \\
\text { easier. }\end{array}$ & & $.688 / .687 / .877$ & \\
\hline & $\mathrm{I} 25$ & I find nanotechnology researches useful. & & $.668 / .687 / .877$ & \\
\hline & $\mathrm{I} 27$ & $\begin{array}{l}\text { I believe that nanotechnology researches are } \\
\text { necessary. }\end{array}$ & & $.640 / .679 / .877$ & \\
\hline & I7 & Nanotechnology contributes to social development. & & $.636 / .650 / .880$ & \\
\hline & I1 & Nanotechnology increases the quality of life. & & $.633 / .596 / .884$ & \\
\hline & $\mathrm{I} 22$ & Nanotechnology is a revolutionary development. & & $.628 / .706 / .875$ & \\
\hline & $\mathrm{I} 45$ & $\begin{array}{l}\text { Nanotechnology helps us to understand the natural } \\
\text { world. }\end{array}$ & & $.568 / .577 / .886$ & \\
\hline \multirow{6}{*}{ 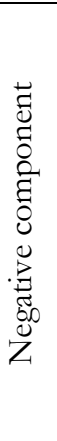 } & $\mathrm{I} 26$ & $\begin{array}{l}\text { I move away from the environment where } \\
\text { nanotechnological applications are talked }\end{array}$ & & & $.762 / .602 / .777$ \\
\hline & $\mathrm{I} 20$ & $\begin{array}{l}\text { I change the channel when I meet news or } \\
\text { advertisement related to nanotechnology on } \\
\text { television. }\end{array}$ & & & $.707 / .639 / .769$ \\
\hline & $\mathrm{I} 12$ & $\begin{array}{l}\text { I get bored when I hear the news, advertising, etc. } \\
\text { about nanotechnology. }\end{array}$ & & & $.680 / .541 / .790$ \\
\hline & $\mathrm{I} 28$ & I get uncomfortable with nanotechnology research. & & & $.630 / .699 / .758$ \\
\hline & $\mathrm{I} 23$ & $\begin{array}{l}\text { I do not explain my opinions in conversations or } \\
\text { discussions about nanotechnology. }\end{array}$ & & & $.624 / .530 / .793$ \\
\hline & I52 & Nanotechnology is not worth learning. & & & $.602 / .468 / .812$ \\
\hline \multicolumn{3}{|c|}{ Eigenvalue } & 5.161 & 4.668 & 3.576 \\
\hline \multicolumn{3}{|c|}{ Ratio of variance explanation ( $\%)$} & $\begin{array}{l}21.503 \\
55.854\end{array}$ & 19.451 & 14.900 \\
\hline \multicolumn{3}{|c|}{ Cr- $\alpha$} & $\begin{array}{l}.899 \\
.926\end{array}$ & .892 & .813 \\
\hline
\end{tabular}

${ }^{*} \mathrm{Cr}-\alpha$ When the Item is Removed

one of the methods based on a single application. It can be used to estimate the reliability of the dichotomously scored items or items with a wide range of scoring weights. It is a measure of item scores' consistency with total test scores (Crocker \& Algina, 2006).

\section{RESULT AND DISCUSSION}

\subsection{Results about the Validity of the Scale}

To collect information about the construct validity of the scale, rotated PCA was used. The suitability of data for PCA was examined with the KMO coefficient and Barlett
Sphericity test. At the end of the examination, the KMO coefficient was calculated as 0.946, and the chi-square test statistic obtained with the Barlett Sphericity test was found significant $\left(\mathrm{X}^{2}=4330.579, \mathrm{df}=276, \mathrm{p}<0.05\right)$. These values were accepted to indicate that the scale's data provided the prerequisites for factor analysis (Kaiser, 1974), and EFA was conducted to reveal the scale's factor structure.

As a result of the EFA performed on 55 items constituting the scale, it was determined that the items were collected in 8 factors having an eigenvalue greater than 1 . These eight factors explained $58.99 \%$ of the variance of the 
attitude variable. After initial EFA, 29 items extract from the scale one by one, and EFA has performed again after each removal. While the items were extracted, three criteria were taken into consideration. The first one is that the item does not load to any factor. As a rule of thumb, it is recommended to interpret the items with factor loadings of 0.30 (Raykov \& Marcoulides, 2008) or 0.40 and above (Field, 2013; Stevens, 2009). For this reason, items that have factor loadings less than 0.40 were excluded from the scale because they did not provide this criterion. The second one is that the item is loaded to more than one factor. For example, if an item is loaded to two factors and the difference between the loads of these factors is less than 0.20 (or 0.15) (Dilorio, 2005), this item is considered as cross-loading and removed from the scale. Lastly, the third one, two items collected under one factor, is also removed from the scale because a factor must contain at least three items (Comrey \& Lee, 1992). In this case, the remaining 24 items were found to have a 3-factor structure with an eigenvalue greater than 1 (Kaiser, 1960).

An eigenvalue represents the amount of information captured by a factor (DeVellis, 2003). The first factor's eigenvalue is 5.161 , which accounts for $21.503 \%$ of the attitude variable's total variance. When we examine the items in this factor consisting of 9 items whose FL ranging from 0.803 to 0.600 , it was found that the items generally contain positive behaviors and emotional tendencies towards nanotechnology, hence the factor called "positive component." The second factor has an eigenvalue of 4.668, accounting for $19.45 \%$ of the attitude variable's total variance. When the items in this factor, consisting of 9 items whose FL are ranging from 0.752 to 0.568 , were examined, it was found that the items generally contained cognitive tendencies for the benefits of nanotechnology in daily life. Hence, the factor is called the "benefit component." Finally, the third factor's eigenvalue is 3.576, which accounts for $14.90 \%$ of the attitude variable's total variance. When the items in this factor consisting of 6 items whose FL ranged from 0.762 to 0.602 were examined, it was found that these items generally had negative behavioral, emotional, and thought tendencies towards nanotechnology. The factor was named as a "negative component" for this reason. These three factors together account for $55.854 \%$ of the attitude variable's total variance. These findings can be used as proof that the developed scale provides construct validity at a satisfactory level and that it has a three-factor structure (see Table 2).

Figure 1 shows the scree plot graph as another widely used method for determining the scale's factor number (Cattell, 1966). The screen test is also based on eigenvalues. Still, it uses their relative values rather than absolute values as a criterion, and then suddenly drop in eigenvalue magnitude can be used for determining the "right" number of factors (Cattell, 1966). Figure 1 shows three factors whose eigenvalues are more than 1 (Kaiser, 1960). The eigenvalues obtained after the varimax rotation techniques are presented in Table 2.

Finally, the parallel analysis, which uses eigenvalue to determine the number of factors, was performed. In this method, many datasets are simulated, each containing the same number of variables and respondents. The difference is that each dataset is made up of completely random data. The eigenvalues are computed for each dataset, and the mean is computed across all of the datasets (Johnson \& Morgan, 2016). The eigenvalues of the factors obtained from the actual data set are compared with the eigenvalues of the factors obtained due to the parallel analysis. As a result, the eigenvalues of the factors derived from the actual data set are expected to be higher (DeVellis, 2003). The results based on 1,000 parallel analyses conducted with O'Connor SPSS syntax (O'Connor, 2000) were represented in Table 3.

Table 3 shows that the first three factors have eigenvalues higher than the mean eigenvalues from the randomly generated datasets. For this reason, the three factors should be evaluated according to parallel analysis. When the harmony between the results obtained from the three methods used to determine the number of factors is considered, it can be concluded that the scale has a threefactor structure.

After analyzing the validity of the structure, ITCs were calculated concerning the item validity of the scale. Result calculations made, ITCs were found to have values ranging between; 0.745 and 0.606 for the items in the first factor, 0.706 and 0.577 for the items in the second factor, and 0.699 and 0.468 for the items the third factor (see Table 2). These values indicate that there is a positive and high level of correlation between item-test scores (Cohen, 1992). These findings can be used as proof that the item validity is sustained and that the items are measuring the same structure.

Table 3 Results obtained from the parallel analysis

\begin{tabular}{lll}
$\begin{array}{l}\text { Factor } \\
\text { number }\end{array}$ & $\begin{array}{l}\text { Eigenvalues } \\
\text { obtained from } \\
\text { real data }\end{array}$ & $\begin{array}{l}\text { Mean eigenvalues from } \\
\mathbf{1 , 0 0 0} \\
\text { datasets of random } \\
\text { numbers }\end{array}$ \\
\hline 1 & $\mathbf{9 . 1 7 8}$ & 1.567259 \\
2 & $\mathbf{2 . 8 2 6}$ & 1.467013 \\
3 & $\mathbf{1 . 4 0 1}$ & 1.398923 \\
4 & .869 & $\mathbf{1 . 3 4 0 3 6 5}$ \\
\hline
\end{tabular}

Table 4 The correlation between the scores of the factors constituting the scale and the scores obtained from the whole scale

\begin{tabular}{lllll}
\hline Factors & Factor 1 & Factor 2 & Factor 3 & $\begin{array}{l}\text { Whole } \\
\text { scale }\end{array}$ \\
\hline Factor 1 & 1.00 & $.556^{* *}$ & $.414^{* *}$ & $.853^{* *}$ \\
Factor 2 & & 1.00 & $.635^{* *}$ & $.866^{* *}$ \\
Factor 3 & & & 1.00 & $.756^{* *}$ \\
\hline
\end{tabular}


Table 5 Descriptive statistics of the items in the final form of the scale

\begin{tabular}{|c|c|c|c|c|c|c|c|}
\hline \multicolumn{4}{|l|}{ Item No } & \multicolumn{2}{|l|}{ Skewness } & \multicolumn{2}{|l|}{ Kurtosis } \\
\hline $\begin{array}{l}\text { In trial } \\
\text { form }\end{array}$ & In final form & $\overline{\mathbf{X}}$ & $\mathrm{s}$ & Statistic & Std. Error & Statistic & Std. Error \\
\hline I1 & I1 & 4.321 & .6737 & -.705 & .126 & .598 & .252 \\
\hline I7 & I2 & 4.116 & .7932 & -1.022 & .126 & 1.831 & .252 \\
\hline I12 & I3 & 3.759 & .9044 & -.864 & .126 & .757 & .252 \\
\hline I13 & I4 & 4.046 & .7336 & -.524 & .126 & .451 & .252 \\
\hline I16 & I5 & 3.142 & 1.0389 & -.085 & .126 & -.444 & .252 \\
\hline I19 & I6 & 3.814 & .8285 & -.291 & .126 & -.166 & .252 \\
\hline I20 & I7 & 3.987 & .8934 & -.860 & .126 & .717 & .252 \\
\hline $\mathrm{I} 22$ & I8 & 3.908 & .8964 & -.651 & .126 & .307 & .252 \\
\hline I23 & I9 & 3.517 & .8961 & -.351 & .126 & .082 & .252 \\
\hline I25 & $\mathrm{I} 10$ & 4.005 & .7441 & -.953 & .126 & 2.260 & .252 \\
\hline I26 & I11 & 4.035 & .8242 & -1.052 & .126 & 1.633 & .252 \\
\hline I27 & I12 & 4.105 & .7912 & -.976 & .126 & 1.553 & .252 \\
\hline $\mathrm{I} 28$ & I13 & 4.172 & .8153 & -1.182 & .126 & 1.918 & .252 \\
\hline I29 & $\mathrm{I} 14$ & 3.103 & 1.0877 & -.069 & .126 & -.289 & .252 \\
\hline I30 & $\mathrm{I} 15$ & 4.040 & .8302 & -.785 & .126 & .733 & .252 \\
\hline I34 & I16 & 3.472 & .9768 & -.434 & .126 & -.108 & .252 \\
\hline I40 & I17 & 3.035 & .9899 & -.071 & .126 & -.618 & .252 \\
\hline I45 & I18 & 3.694 & .8536 & -.435 & .126 & .265 & .252 \\
\hline I 48 & I19 & 3.485 & .8717 & -.481 & .126 & .434 & .252 \\
\hline I49 & $\mathrm{I} 20$ & 3.054 & 1.0303 & -.036 & .126 & -.590 & .252 \\
\hline I52 & I 21 & 4.005 & 1.0347 & -1.008 & .126 & .352 & .252 \\
\hline I53 & I22 & 2.919 & 1.0074 & .180 & .126 & -.374 & .252 \\
\hline I54 & $\mathrm{I} 23$ & 3.075 & 1.0211 & -.030 & .126 & -.501 & .252 \\
\hline I55 & I24 & 3.395 & 1.0586 & -.447 & .126 & -.281 & .252 \\
\hline
\end{tabular}

The correlation between the scores of the factors constituting the scale and the scores obtained from the whole scale indicates the presence of a high level and meaningful relationship $(0.414 \leq \mathrm{r} \leq 0.866, \mathrm{p}<0.01)$ in the positive direction (Cohen, 1992). This finding can be regarded as a demonstration that the three factors establishing the scale are components of the attitude towards nanotechnology. The detailed data on FL of the items and ITCs are presented in Table 2. The correlation coefficients between the scores of the factors constituting the scale and the scores obtained from the whole scale are presented in Table 4.

Verification of the model for the 3-component structure obtained from the EFA was tested by applying CFA through the LISREL software. For the fit indices, the values of $\chi^{2} / \mathrm{df}$ (Chi-Square/Degree of Freedom), Root Mean Square Error of Approximation, Normed Fit Index, Comparative Fit Index, Adjusted Goodness-of-Fit Index, Goodness-of-Fit Index, and Standardized Root Mean Square Residual were also examined. The goodness-of-fit indices obtained without performing any modification on the model as a result of CFA performed on the structure consisting of three factors, and 24 items are as follows: $\chi^{2}=983.46, \mathrm{df}=249, \chi^{2} / \mathrm{df}=3.95(\mathrm{p}=0.000)$, Root Mean Square Error of Approximation $=0.062$, Normed Fit
Index $=0.96$, Comparative Fit Index $=0.97$, Adjusted Goodness-of-Fit $\quad$ Index $=0.88, \quad$ Goodness-of-Fit Index $=0.90$, Standardized Root Mean Square Residual $=0.053]$. When the model's goodness-of-fit indices were examined, it can be said that the ratio of Chi-square value to the degree of freedom $\left(\chi^{2} / \mathrm{df}=3.95\right)$ was acceptable (Kline, 2005), Root Mean Square Error of Approximation had a good fitness (Brown, 2006; Jöreskog \& Sörbom, 1993), Comparative Fit Index and Normed Fit Index values had excellent fitness (Sümer, 2000; Thompson, 2004), Standardized Root Mean Square Residual value had an good fitness (Brown, 2006; Byrne, 1994), the Goodness-ofFit Index value has an excellent agreement, and Adjusted Goodness-of-Fit Index values were at acceptable levels (Jöreskog \& Sörbom, 1993). In conclusion, these findings can be interpreted that EFA's model agrees with the structure obtained by CFA. The model obtained as a result of CFA was given in Figure 2 with standardized solution values. Finally, the numbers of the items in the final form of the scale and the mean, standard deviation, skewness, and kurtosis values are presented in Table 5.

\subsection{Results about the Reliability of the Scale}

The $\mathrm{Cr}-\alpha$ reliability coefficient was calculated to provide evidence of the reliability of the scale. In this process, all of the factors establishing the scale and the whole scale are 


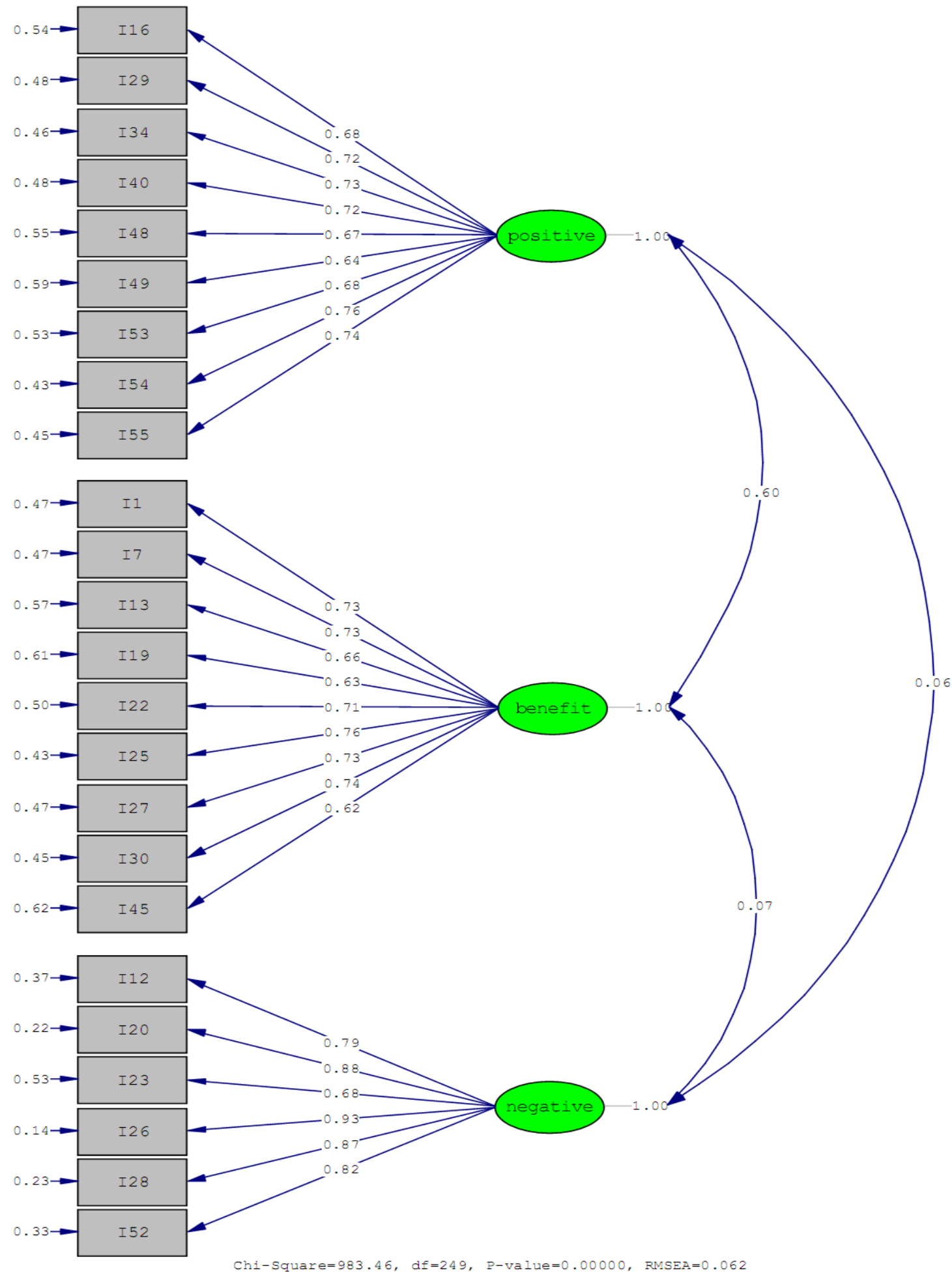

Figure 2 The model obtained as a result of confirmatory factor analysis

handled separately. $\mathrm{Cr}-\alpha$ reliability of the first factor is calculated as 0.899 , the second factor as 0.892 , the third factor as 0.813 , and the whole scale as 0.926 . These findings can be used as evidence that the scale has a satisfactory level of reliability (Bland \& Altman, 1997). The details of the data obtained from the reliability analysis are presented in Table 2.

\subsection{Discussion}

Nieswandt (2005) stated that an overview of attitude definitions in related literature shows that attitude is not a uni-directional term but a multi-directional construct consisting of affective, cognitive, and behavioral components. Therefore, it is a selection of researchers to define their understanding of attitude depending on the 
research objectives. In this study, based on the multidirectional structure given in the literature, the items were written for all cognitive, affective, and behavioral components in the item writing process. According to the findings obtained from the analysis, the developed scale also included items for three dimensions. It is considered that these findings support the view of the multi-directional structure. It was also found that these components' items were placed in different proportions in the factors forming the scale. The items related to cognitive and behavioral components were relatively higher. According to Erkuş (2003), the number and structure of attitude components may vary depending on the statistics used in structure validation, the selection of indicators used to measure the attitude structure's components, and the nature of the attitude object used.

Within this study's scope, a new scale that aims to measure pre-service science teachers' attitudes towards nanotechnology has been developed. Participants' attitudes towards nanotechnology at various ages and levels of education were measured using various scales that have been developed. For example, Kurnaz and Bayraktar (2012) have developed a scale that can determine high school students' attitudes towards nanotechnology subjects. The developed scale has a 2-factor structure consisting of 19 items. These factors, which account for $73.3 \%$ of the attitude variable's total variance, were named by researchers as "valuation to nanotechnology" and "nanotechnology awareness." The $\mathrm{Cr}-\alpha$ reliability coefficient of the scale was 0.88 .

Moreover, in the study conducted by Seçken (2009), a measurement tool was developed to determine pre-service chemistry teachers' attitudes towards nanotechnology. The developed scale has a 4-factor structure consisting of 16 items. These factors, which account for $59.89 \%$ of the attitude variable's total variance, were named by the researcher as "labor," "anxiety," "life," and "education." The Cr- $\alpha$ reliability coefficient of the scale was 0.86 .

Furthermore, Lan (2012) has developed a scale that can measure K-12 teachers' attitudes towards nanotechnology. The developed scale has a 3-factor structure consisting of 23 items. These factors, which account for $64.11 \%$ of the attitude variable's total variance, were named by the researcher as "the importance of nanotechnology," "affective tendencies in science teaching," and "behavioral tendencies towards teaching nanotechnology." The $\mathrm{Cr}-\alpha$ reliability coefficient of the scale was 0.94 .

Although the items in the factors of the scale developed in the present study are similar to the items in the related studies' sub-dimensions, these scales differ in terms of the obtained factor structures and naming of the factors. It is seen that the structure of attitude scales for nanotechnology differs considerably from each other, and a complete consensus among researchers cannot be obtained from this point of view. That may be due to different perspectives that researchers have adopted in the scale development process. Besides, due to the limited number of Likert-type scale development studies that can be used to determine attitudes towards nanotechnology, a clear and standard structure may not yet be achieved. The current study's focus group is PSSFT, which is a different aspect than the studies in the literature. It is thought that the study can contribute to the related literature in this regard.

\section{CONCLUSION}

In this study, a scale was developed that can be used to measure the attitudes of PSSFT towards nanotechnology. It has been determined that the developed scale has a 3factor structure consisting of 24 items. The researchers named these factors as "positive component," "benefit component," and "negative component." The factors' eigenvalues are determined as 5.161, 4.668, and 3.576, respectively, and they account for $21.503 \%, 19.451 \%$, and $14.90 \%$ of the attitude variable's total variance, respectively. Also, three factors account for $55.854 \%$ of the attitude variable's total variance. As a result of the reliability analysis conducted to establish evidence of the scale's reliability, the $\mathrm{Cr}-\alpha$ reliability of the scale was found to be 0.926 ; and $\mathrm{Cr}-\alpha$ reliability for each factor found as 0.899 , 0.892 , and 0.813 , respectively. The lowest score that can be taken from the scale is 24 , and the highest score is 120 . It can be said that the attitude towards nanotechnology increases as the score obtained from the scale increases. This study shows that the psychometric properties of the nanotechnology attitude scale have a valid and reliable structure to measure the attitudes of PSSFT towards nanotechnology.

However, this study has several limitations. First, the nanotechnology attitude scale findings presented in this study are limited to the data obtained from the study group selected from Turkey's Central Anatolia region. In further studies, the researchers using different groups with similar characteristics can contribute to generalizing the results of this study and the validity and reliability of the scale. Second, the PSSFT is identified as the target group in developing the scale in this study. If the scale is intended to use for pre-service teachers or teachers in different areas and different countries or cultures, validity and reliability analyses should be performed with the data that is going to be obtained from these groups. As another important point, to better understand the structure of the attitude towards nanotechnology, researchers can develop an attitude scale for participants of different ages and education levels or apply the scales available in the literature to contribute to these scales' validity and reliability. 


\section{NOTES}

A part of this study was presented at the III. INES International Education and Social Science Congress in Alanya, 28 April-1 May, 2018.

\section{ABBREVIATIONS}

EFA, Exploratory Factor Analysis; CFA, Confirmatory Factor Analysis; KMO, The Kaiser-Meyer Olkin; SPSS, Statistical Package for the Social Sciences; LISREL, Linear Structural Relation Statistics Package Program; FL, Factor Loads; ITCs, Item-Test Correlations; Cr- $\alpha$ WIR, Cr- $\alpha$ When the Item is Removed; PSSFT, Pre-service Science Fields Teachers; PCA, Principal Component Analysis.

\section{REFERENCES}

Allport, G. W. (1935). Attitudes. In C. Murchison. (Ed.), Handbook of social psychology (pp. 798-844), Worcester, MA: Clark University Press.

Bainbridge, W. S. (2002). Public attitudes toward nanotechnology. Journal of Nanoparticle Research, 4, 561-570. doi: 10.1023/A:1022805516652

Bhushan, B. (2010). Introduction to nanotechnology. In B. Bhushan. (Ed.), Springer Handbook of Nanotechnology (pp. 1-19). Springer Handbooks. Springer, Berlin, Heidelberg.

Bland, J. M., \& Altman, D. G. (1997). Statistics notes: Cronbach's alpha. BMJ, 314, 572. doi:10.1136/bmi.314.7080.572

Brickhouse, N. W. (1990). Teacher beliefs about the nature of science and their relationship to classroom practices. Journal of Teacher Education, 41, 53-62.

Brown, T. A. (2006). Confirmatory factor analysis for applied research. New York: Guilford Press.

Byrne, B. M. (1994). Structural equation modeling with EQS and EQS/Windows: Basic concepts, applications, and programming. Thousand Oaks, CA: Sage Publications.

Cattell, R. B. (1966). The scree test for the number of factors. Multivariate Behavioral Research, 1(2), 245-276.

Çıracı, S. (2006). Ulusal nanoteknoloji araştırma merkezi (UNAM): Nanobilim ve nanoteknolojide Türkiye'nin bir mükemmeliyet merkezi. Bilim ve Teknik: Yeni Ufuklara, 2-4. http://www.bilimteknik.tubitak.gov.tr/system/files/nanoteknoloj i t.pdf

Cohen, J. (1992). A power primer. Psychological Bulletin, 112(1), 155-159. doi:10.1037/0033-2909.112.1.155

Comrey, A. L., \& Lee, H. B. (1992). A first course in factor analysis (2nd ed.). New Jersey: Lawrence Erlbaum Associates.

Crocker, L., \& Algina, J. (1986). Introduction to classical and modern test theory. Holt, Rinehart and Winston, 6277 Sea Harbor Drive, Orlando, FL 32887.

DeVellis, R. F. (2016). Scale development: Theory and applications (Vol. 26). Sage publications.

Dilorio, C. (2005). Measurement in health behaviour: Methods for research and education. San Francisco: Jossey-Bass.

Droba, D. D. (1933). The nature of attitude. Journal of Social Psychology, 4(4), 444-463. doi: 10.1080/00224545.1933.9919338

Erkus, A. (2003). Psikometri uzerine yazilar. Turk Psikologlar Dernegi Yayinlari, 24, 34-72.

Field, A. (2013). Discovering statistics using IBM SPSS Statistics (4th ed.). London: Sage Publications.

Fraenkel, J. R., \& Wallen, N. E. (2009). How to Design and Evaluate Research in Education (7th Edition). New York: McGraw-Hill.

İnceoğlu, M. (2004). Tutum alg1 iletişim (Attitude, perception, communication). Ankara: Elips Kitap Kesit Tanttm.

Johnson, R. L., \& Morgan, G. B. (2016). Survey Scales: A Guide to Development, Analysis, and Reporting. New York: The Guilford Press.
Jöreskog, K. G., \& Sörbom, D. (1993). LISREL 8: Structural equation modeling with the SIMPLIS command language. Chicago: SSI Scientific Software International Inc.

Jöreskog. K. G., \& Sörbom. D. (1978). Analysis of linear structural relationships by the method of maximum likelihood. Chicago: National Educational Resources.

Kağitçibaşi, Ç., \& Cemalcilar, Z. (2014). Dünden bugüne insan ve insanlar: Sosyal psikolojiye giriş. Baske-Cilt: Sistem Matbaacılı. Yulanlı ayazma Yolu, (8), 146-147.

Kaiser, H. F. (1960). The application of electronic computers to factor analysis. Educational and Psychological Measurement, 20, 141-151. doi:10.1177/001316446002000116

Kaiser, H. F. (1974). An index of factorial simplicity. Psychometrika, 39, 31-36. doi:10.1007/BF02291575

Kaiser, H. F. (1970). A second-generation little jiffy. Psychometrika, 35, 401-415.

Kline, R. B. (2005). Principles and practice of structural equation modeling (2nd ed.). New York: Guilford Press.

Kuppuswamy, B. (1965). An introduction to social psychology. Bombay, India: Asia publishing house.

Kurnaz, M. A., \& Bayraktar, G. (2012). Nanoteknoloji tutum ölçeği: Geliștirilmesi, geçerliliği ve güvenilirliği. Bayburt Universitesi Ë̆itim Fakëltesi Dergisi, 7(1), 41-53. http://dergipark.gov.tr/befdergi/issue/23151/247273

Lan, Y-L. (2012). Development of an attitude scale to assess K-12 teachers' attitudes toward nanotechnology. International Journal of Science Education, 34(8), 1189-1210, doi:10.1080/09500693.2011.651657

Lee, C., Scheufele, D. A., \& Lewenstein, B. V. (2005). Public attitudes toward emerging technologies. Science Communication, 27(2), 240267, doi:10.1177/1075547005281474

Liang, X., Ho, S. S., Brossard, D., Xenos, M. A., Scheufele, D. A., Anderson, A. A., Hao, X., \& He, X. (2015). Value predispositions as perceptual filters: Comparing of public attitudes toward nanotechnology in the United States and Singapore. Public Understanding of Science, 24(5) 582-600, doi.org/10.1177/0963662513510858

Nerlich, B., Clarke, D. D., \& Ulph, F. (2007). Risks and benefits of nanotechnology: How young adults perceive possible advances in nanomedicine compared with conventional treatments. Health, Risk \& Society, 9(2), 159-171, doi:10.1080/13698570701306856

Nieswandt M. (2005). Attitudes toward science: A review of the field. In: Cobern W.W. et al. (Eds.) Beyond cartesian dualism: Encountering affect in the teaching and learning of science (pp.41-52). Science \& Technology Education Library, vol 29. Springer, Dordrecht.

O'Connor, B. P. (2000). SPSS and SAS programs for determining the number of components using parallel analysis and Velicer's MAP test. Behavior Research Methods, Instrumentation, and Computers, 32, 396402. doi.org/10.3758/BF03200807

Oppenheim, A. N. (2001). Questionnaire design, interviewing and attitude measurement. London: Continuum.

Pajares, M. F. (1992). Teacher' beliefs and educational research: cleaning up a messy construct. Review of Educational Research. 62, 307-332. https://doi.org/10.3102/00346543062003307

Pedhazur, E. J., \& Schmelkin, L. P. (2013). Measurement, design, and analysis: An integrated approach. Psychology press.

Pett, M. A., Lackey, N. R., \& Sullivan, J. J. (2003). Making sense of factor analysis: The use of factor analysis for instrument development in bealth care research. CA: Sage.

Raykov, T., \& Marcoulides, G. A. (2008). An introduction to applied multivariate analysis. New York: Routledge-Taylor \& Francis.

Roco, M. C., \& Bainbridge, W. S. (2001). Societal implications of nanoscience and nanotechnology. NSET Workshop Report, Arlington, Virginia.

Seçken, N. (2009). Attitudes scale towards "nano technology" for chemistry teachers. Journal of Baltic Science Education, 8(3), 157-171. http://oaji.net/articles/2014/987-1404740194.pdf 
Stephens, L. F. (2005). News narratives about nano S \& T in major U.S. and non-U.S. newspapers. Science Communication, 27(2), 175-199. doi: $10.1177 / 1075547005281520$

Stevens, J. P. (2009). Applied multivariate statistics for the social sciences (5th ed.). Taylor \& Francis Group.

Sümer, N. (2000). Yapisal Eșitlik Modelleri: Temel Kavramlar ve Örnek Uygulamalar. Türk Psikoloji Yazilari. 3(6), 49-74.

Tabachnick, B., \& Fidell, L. (2013). Using multivariate statistics, (6th Ed). Saddle River, NJ: Pearson Education.

Tessman, J. M. (2009). Students' conceptions of nanoscience phemonena: The beginning of a nanoscience concept inventory [Doctoral dissertation], Purdue University, West Lafayette, Indiana.

Tezbaşaran, A. (2008). Likert tipi ölçek hazırlama kılavuzu (3. sürüm ekitap). Erişsim Taribi, 15. Ankara: Türk Psikologlar Derneği Publications.

Thompson, B. (2004). Exploratory and confirmatory factor analysis: Understanding concepts and applications. Washington, DC: American Psychological Association, doi:10.1037/10694-000

Thurstone, L. L. (1931). The measurement of social attitudes. The Journal of Abnormal and Social Psychology, 26(3), 249-269, doi: $10.1037 / \mathrm{h} 0070363$

Tinsley, H. E. A., \& Tinsley, D. J. (1987). Uses of factor analysis in counseling psychology research. Journal of Counselling Psychology, 34(4), 414-424.

Zhang, J., Wang, G., \& Lin, D. (2015). High support for nanotechnology in China: A case study in Dalian. Science and Public Policy, 43(1), 115 127, doi: $10.1093 /$ scipol/scv020 